\title{
ERRATUM
}

Jian Yang $\cdot$ Hui Ye $\cdot$ Jing-yu Yang $\cdot$ David Zhang

\section{A new LDA-KL combined method for feature extraction and its generalisation}

Published online: 25 June 2004

(C) Springer-Verlag London Limited 2004

\section{Pattern Anal Applic (2004) 7:40-50}

Due to an unfortunate error, the name of the third author, Jing-yu Yang, was deleted from the author list when the proof corrections were carried out.
The author list should be as follows: Jian Yang, Hui Ye, Jing-yu Yang, David Zhang

The online version of the original article can be found at http:// dx.doi.org/10.1007/s10044-004-0205-6

J. Yang $(\bowtie) \cdot H$. Ye $\cdot$ J. Yang

Department of Computer Science,

Nanjing University of Science and Technology,

210094 Nanjing, People's Republic of China

E-mail: tuqingh@mail.njust.edu.cn

Tel.: + 86-25-4316840

Fax: + 86-25-431-5510

D. Zhang

Department of Computing,

Hong Kong Polytechnic University,

Kowloon, Hong Kong 